\title{
Analyst
}

PAPER
Check for updates

Cite this: Analyst, 2019, 144, 6352

\section{A synchrotron-based infrared microspectroscopy study on the cellular response induced by gold nanoparticles combined with X-ray irradiations on F98 and U87-MG glioma cell lines}

\author{
I. Martínez-Rovira, (D)*a O. Seksek (D) ${ }^{b, c}$ and I. Yousef (D) ${ }^{a}$
}

The inclusion of nanoparticles (NP) in radiotherapy has been shown to increase the damaging effect on tumor cells. However, the mechanisms of action of NP combined with radiotherapy, and the influence of NP parameters and cell type on their radiosensitization capability at molecular and cellular levels still remain unclear. Gold NP (AuNP) have become particularly popular due to their multiple advantages. Within this context, our research work aimed to study the biochemical radiosensitization capacity of F98 and U87-MG glioma cell lines to $1.9 \mathrm{~nm}$ AuNP combined with X-ray irradiation. For this purpose, synchrotron-based infrared microspectroscopy (SR-FTIRM) was used as a powerful tool for biochemical composition and treatment response assessment of cells at a single-cell level. SR-FTIRM data, supported by multivariate analysis, revealed clear AuNP-induced changes in the DNA, protein and lipid spectral regions. The AuNP-related biochemical alterations appear prior to the irradiation, which gave us a first indication on the AuNP radiosensitization action. Biochemical modifications induced by the AuNP in the presence of radiotherapy irradiations include enhanced conformational changes in the protein secondary structures, variations in the intensity and position in the phosphodiester bands, and changes in the $\mathrm{CH}_{2}$ and $\mathrm{CH}_{3}$ stretching modes. These changes are better manifested at 24 hours post-irradiation time. SR-FTIRM results showed a clear heterogeneity in the biochemical cell response, probably due to the distinct cellNP interactions and thus, to different DNA damage and cell death processes.
Received 17th June 2019, Accepted 28th August 2019

DOI: 10.1039/c9an01109a

rsc.li/analyst
Among all types of NP, gold $(Z=79)$ nanoparticles (AuNP) are particularly attractive since they are inert, highly biocompatible, relatively easy to synthesize and functionalise, and they have an increased cross section for photoelectric photon absorption (specially for low X-ray energies). ${ }^{1,4,5,8,9}$ The latter enhances the secondary electron production (short-range photoelectrons and Auger electrons) and the local dose deposition near the NP. ${ }^{10}$ At the same time, these electrons can further increase the generation of reactive oxygen species (ROS) and electron emission from nearby NP. Besides the pure physical effects, the presence of NP itself can also increase the ROS production, and thus, the cellular damage., ${ }^{4,11}$

However, the radiosensitization mechanisms at molecular and cellular levels still remain unclear. Results from the previous biological studies indicated that radiosensitization effects might be driven by biological mechanisms induced by the NP rather than by physical (dose enhancement) effects. These mechanisms include oxidative stress, DNA damage induction, cell cycle effects and potential interference with cell communication. ${ }^{12-16}$ This, along with the influence of many other parameters like NP size, shape and coating, which at the same time influence the NP distribution inside the cells, as

\footnotetext{
${ }^{a}$ MIRAS Beamline BL01, ALBA-CELLS Synchrotron, Carrer de la Llum 2-26, 08290 Cerdanyola del Vallès, Spain. E-mail: immamartinez@gmail.com

${ }^{b}$ Laboratoire d'Imagerie et Modélisation en Neurobiologie et Cancérologie (IMNC), Centre National de la Recherche Scientifique (CNRS); Université Paris Sud, Université Paris-Saclay, Campus Universitaire, Bât. 440, 15 rue Georges Clemenceau, F-91400 Orsay, France

${ }^{c}$ Université de Paris, IMNC, F-91400 Orsay, France
} 
well as the distinct cellular responses, largely complicates research on radiosensitization effects of NP. ${ }^{4}$

Fourier transform infrared microspectroscopy (FTIRM) can shed some light on the mechanisms involved in the radiosensitization effects of NP. FTIRM is a non-destructive vibrational technique for the analysis of biological samples. ${ }^{17}$ IR active molecular bonds of the main cell biomolecules change the dipole moment as a result of the vibration that occurs when infrared light is absorbed. The mid infrared spectral region is the most important for studying biological specimens since it includes the so-called 'fingerprint region' and the 'lipids region', which provides nucleic acid, protein, lipid, carbohydrate composition and/or conformational changes. This information enables the assessment of cell functionality, cell division, differentiation, growth and metabolism. ${ }^{17-21}$

Within this context, the objective of this study is to use synchrotron-based FTIRM (SR-FTIRM) to disentangle radiosensitization effects of gold NP (1.9 nm AuroVist $\left.{ }^{\mathrm{TM}}\right)^{22}$ in glioma cells. Despite the current treatment options, high grade glioma has poor prognosis in humans and thus, patient outcome could benefit from the enhanced therapeutic index of combined RT-NP modalities. Gaining new insights into the radiosensitization effects of AuNP in glioma cells is essential to progress on the development of NP-based therapeutics. In this work, we present SR-FTIRM data on F98 and U87-MG glioma cell lines to assess distinct cellular responses as a function of the cell type. The highly brilliant infrared source used in SR-FTIRM provided high spatial resolution and high quality information required for the single-cell analysis of our work. To the best of our knowledge, this is the first study that evaluates cell radiosensitization to AuNP by using SR-FTIRM.

\section{Materials and methods}

\subsection{Cell culture: F98 and U87-MG}

The response of the two glioma cell lines, F98 (rat, ATCC® CRL-2397) and U87-MG (human, ATCC® HTB-14), was studied. The F98 glioma rat cell line simulates the behavior of glioblastoma tumors due to its highly invasive pattern of growth within the brain and low immunogenicity; it is commonly used to evaluate the effectiveness of several therapeutic agents. $^{23}$ The U87-MG human tumor model presents a nondiffusely infiltrative growth pattern and it is one of the most widely used cell lines, especially for anti-angiogenic therapy studies. $^{24}$

Both cell lines were purchased from LGC Standards (Molsheim, France). They were maintained and passaged in a high glucose $\left(4.5 \mathrm{~g} \mathrm{~L}^{-1}\right)$ Gibco $^{\mathrm{TM}}$ DMEM medium (Life Technologies SAS, Courtaboeuf, France) supplemented with $1 \mathrm{mM}$ GlutaMAX ${ }^{\mathrm{TM}}, 1 \mathrm{mM}$ sodium pyruvate, $10 \%$ fetal calf serum and $1 \%$ penicillin-streptomycin (10000 U each), at $37{ }^{\circ} \mathrm{C}$ and $5 \% \mathrm{CO}_{2}$. On the day prior to the treatments, $10^{5}$ cells per well were seeded in 6-well plates and incubated overnight.

\subsection{Gold nanoparticles}

Gold NP (1.9 nm AuroVist $\left.{ }^{\mathrm{TM}}\right)$ were purchased from Nanoprobes (Yaphank, NY, USA). The potential of these NP has been proved in previous biological studies. ${ }^{1,4,25,26}$

A stock solution was extemporaneously prepared by mixing the AuNP (40 mg of gold) with $1 \mathrm{~mL}$ ultrapure water (Millipore Direct Q8). After rapid dissolution, the solution was filtered through a $0.2 \mu \mathrm{m}$ centrifugal filter at $15000 \mathrm{~g}$ for 8 minutes and kept at $4{ }^{\circ} \mathrm{C}$. For cell treatment, the AuNP solution was diluted in fresh supplemented cell medium at a final concentration of $12 \mu \mathrm{M}\left(500 \mu \mathrm{g} \mathrm{mL}^{-1}\right){ }^{25}$ The cells were then incubated at $37{ }^{\circ} \mathrm{C}$ and $5 \% \quad \mathrm{CO}_{2}$ for 24 hours. $^{25}$ Before the irradiation protocol, the AuNP-containing medium was discarded and replaced by $3 \mathrm{~mL}$ of fresh medium.

\subsection{X-ray irradiation}

Kilovoltage irradiations were performed at the Curie Institute (Orsay, France) with an X-ray unit (XRAD 320, Cegelec). The mean energy of this X-ray generator is $90 \mathrm{keV}$ and the dose rate is $1.1 \mathrm{~Gy} \mathrm{~min}^{-1}$. Each well plate was irradiated separately at 5 , 10 and $20 \mathrm{~Gy}$, respectively, for both cell lines, with and without AuNP. Two non-irradiated wells (0 Gy, without and with AuNP) were kept for controls. Just after irradiation, the medium was replaced by fresh medium.

\subsection{SR-FTIRM sample preparation}

For SR-FTIRM measurements, samples had to undergo a specific preparation protocol, i.e. cell fixation and deposition on infrared transparent calcium fluoride $\left(\mathrm{CaF}_{2}\right)$ cover glasses. ${ }^{21,27}$ The cells were fixed at two post-irradiation times: after the irradiation $\left(T_{\mathrm{oh}}\right)$ to evaluate immediate treatmentinduced effects, and after 24 hours $\left(T_{24 \mathrm{~h}}\right)$ to assess the cellular response from the treatment.

For both fixation times $\left(T_{\mathrm{Oh}}\right.$ and $\left.T_{24 \mathrm{~h}}\right)$, the medium was removed and kept in order to collect floating cells. Then, $100 \mu \mathrm{L}$ of $0.05 \%$ trypsin-EDTA solution was added into each well and incubated for $5 \mathrm{~min}$. After cell detachment, the medium with floating cells was added back to the trypsinized cells, and $500 \mu \mathrm{L}$ of fresh supplemented medium was added. The cell suspension was then centrifuged at $1500 \mathrm{rpm}$ for 5 min at $4{ }^{\circ} \mathrm{C}$. The cellular pellet was rinsed with PBS, and resuspended in $10 \%$ formalin neutral buffered solution (Sigma-Aldrich). After 1 hour at room temperature, the samples were centrifuged at $1500 \mathrm{rpm}$ for $5 \mathrm{~min}$ and the pellet was washed 3 times in Millipore water. The final cell suspensions in water were kept at $4{ }^{\circ} \mathrm{C}$ until cytospinned down onto $0.5 \mathrm{~mm}$ thick infrared transparent $\mathrm{CaF}_{2}$ slides using a Cytospin 4 centrifuge (ThermoFisher; $700 \mathrm{rpm}$ for $5 \mathrm{~min}$ ). Dried cells were then analyzed by SR-FTIRM.

\subsection{SR-FTIRM at ALBA Synchrotron}

SR-FTIRM experiments were performed at the infrared beamline MIRAS of the ALBA-CELLS synchrotron light source using the Hyperion 3000 microscope coupled to a Vertex 70 spectrometer (Bruker Optik GmbH, Germany). The measurements 
were performed in the transmission mode of operation of the FTIR microscope. This microscope is operating with a $36 \times$ Schwarzschild magnification objective $(\mathrm{NA}=0.65)$ coupled to a $36 \times$ magnification condenser. The microscope is furnished with a liquid nitrogen cooled $50 \mu \mathrm{m}$ mercury cadmium telluride (MCT) detector. Around 70-100 cells were randomly collected from each sample condition. Single point maps of individual cells were collected in the $3800-900 \mathrm{~cm}^{-1}$ mid infrared range at $4 \mathrm{~cm}^{-1}$ spectral resolution with 256 co-added scans per spectrum. All spectra were obtained using a single masking aperture size of $8 \mu \mathrm{m} \times 8 \mu \mathrm{m}$. Reference or background spectra were collected under the same acquisition parameters of the sample. In particular, measurement in an empty region on the $\mathrm{CaF}_{2}$ slides (without cells) was repeated every 10 cell measurements, in order to take into account the differences under the ambient conditions along the measurements. The final cell absorbance spectrum was obtained by subtracting the reference spectrum from the raw cell spectra. The subtraction was done directly (automatically) using OPUS 7.5 software (Bruker Optik GmbH, Germany).

\subsection{SR-FTIRM data analysis}

Differences in the spectral features were evaluated by Principal Component Analysis (PCA) using Unscrambler X (CAMO Software AS, Norway). PCA was performed on vector normalized second derivative spectra (Savitzky-Golay algorithm; 3rd polynomial order). Vector normalization and PCA were separately applied in the $3100-2800$ and $1800-1000 \mathrm{~cm}^{-1}$ spectral regions.

Raw spectra were corrected following the rubber band method (32 baseline points) using OPUS 7.5 (Bruker Optik $\mathrm{GmbH}$, Germany) in order to assess the area under several spectral bands reported hereafter and represented in Fig. 1.

- Methyl asymmetric stretching: 2980-2945 cm ${ }^{-1}\left(\mathrm{CH}_{3}\right)$.

- Methylene asymmetric stretching: $2945-2900 \mathrm{~cm}^{-1}\left(\mathrm{CH}_{2}\right)$.

- Amide I: $1710-1598 \mathrm{~cm}^{-1}$ (AI).

- Amide II: $1590-1483 \mathrm{~cm}^{-1}$ (AII).
- Phosphate I: $1270-1186 \mathrm{~cm}^{-1}$ (PhI).

- Phosphate II: 1146-1004 $\mathrm{cm}^{-1}$ (PhII).

The total area under the spectra (except the 2800-1800 $\mathrm{cm}^{-1}$ region) was associated with the total cell biomass (Cell) following previous studies. ${ }^{28,29}$ Violin plots showing the probability density of the data for PhI/AII, PhII/ AII, AI/AII and $\mathrm{CH}_{2} / \mathrm{CH}_{3}$ ratios were generated, since these ratios have been reported to provide valuable information on cell response after treatments. ${ }^{28,30,31}$

\subsection{Microphotography}

F98 and U87-MG cells were seeded in a $35 \mathrm{~mm}$ polystyrene Petri dishes using the same NP concentration and NP incubation time as for SR-FTIRM measurements. After treatment, the cells were washed in fresh medium and microscopy image acquisition was performed using a $10 \times$ Nikon water-immersion DIC objective placed on an Eclipse 80i Nikon microscope (Scop Pro, Marolles-en-Hurepoix, France), which is equipped with a Zyla 5.5 MPX Andor SCMOS cooled camera (Scop Pro, France) and MetaMorph acquisition software (Molecular Devices, Sunnyvale, CA).

\subsection{Cell viability assay}

Metabolic activity was evaluated using the resazurin-resorufin cytotoxicity assay. ${ }^{32,33}$ Briefly, after irradiation treatment, the cells were harvested in each well of the 6-well plate by using the usual trypsin-EDTA procedure. The cells were counted and $100 \mu \mathrm{L}$ of $10^{5}$ cells per $\mathrm{mL}$ were seeded in 96-well microplates and incubated for 24 hours at $37^{\circ} \mathrm{C}$. After 24 hours, the medium was discarded and replaced by fresh medium containing $30 \mu \mathrm{g} \mathrm{mL}^{-1}$ of resazurin (from a filtered $1.2 \mathrm{mg} \mathrm{mL}^{-1}$ stock solution in PBS). The cells were incubated for 3 hours at $37^{\circ} \mathrm{C}$, and the fluorescence intensity measurement of each well was performed using a Fluoroskan Ascent FL microplate reader (Thermo Fisher Scientific, Illkirch, France) at 530 and $590 \mathrm{~nm}$ for excitation and emission, respectively. The percentage of the metabolic activity of the cell populations was evaluated as the
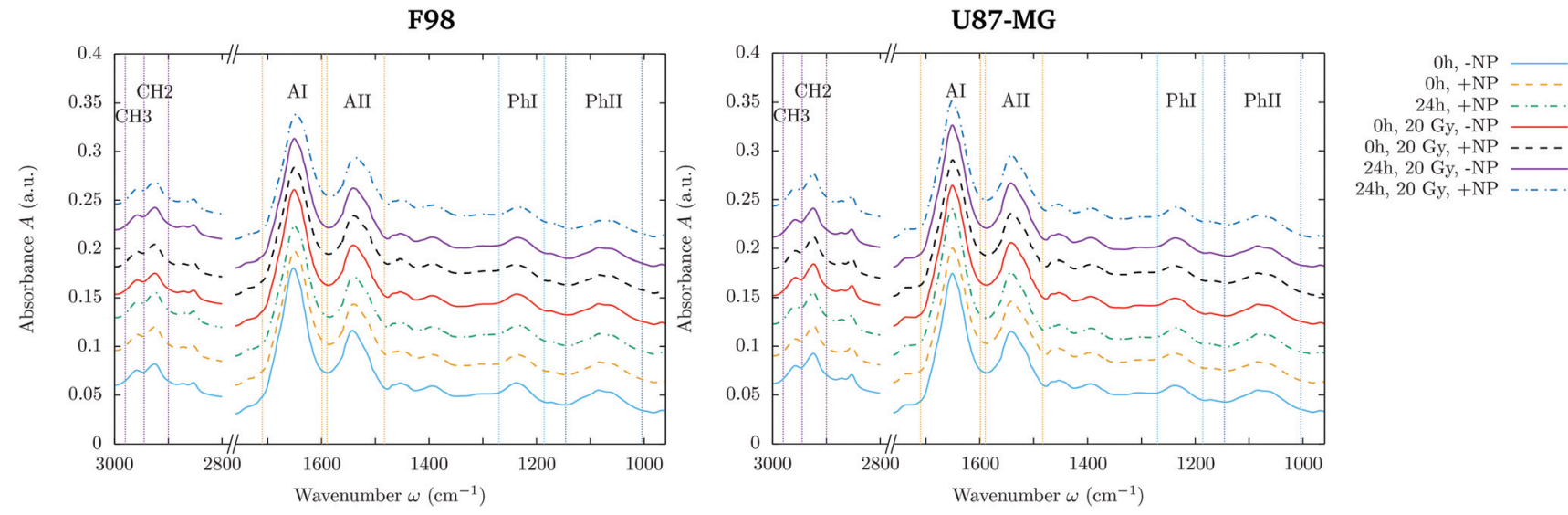

Fig. 1 F98 (left) and U87-MG (right) glioma cells: averaged absorbance spectra for controls and treated cells, in the presence ('+NP') and absence ('-NP') of nanoparticles at two post-irradiation fixation times ( $0 \mathrm{~h}$ and $24 \mathrm{~h}$ ) irradiated with a dose of $20 \mathrm{~Gy}$. The limits of the band/regions described in section 2.6 are shown. For clarity, the different averaged absorbance spectra have been shifted along the absorbance axis. 
ratio of the fluorescence intensity after treatment to the control fluorescence intensity.

\section{Results and discussion}

Microphotography images for the qualitative assessment of intracellular NP localization are shown in section 3.1. Then, the results of SR-FTIRM analysis and cell viability assays are presented for both cell lines (F98 and U87-MG) and several irradiation doses (from 0 to $20 \mathrm{~Gy}$ ) in the presence $(+\mathrm{NP})$ and absence (-NP) of AuNP and two post-irradiation fixation times ( $T_{0 \mathrm{~h}}$ and $T_{24 \mathrm{~h}}$ ). SR-FTIRM details on the biochemical effects induced by the AuNP without ( 0 Gy) and with radiation are presented in sections 3.2 and 3.3, respectively. The results of cell viability assays are reported in section 3.4.

\subsection{Microphotography for intracellular NP localization assessment}

Fig. 2 shows the bright field micrographs of F98 and U87-MG cells, respectively, with and without AuNP. While both cell lines show different morphologies (F98 is elongated and U87MG is flatter and more spread on the cell support), nuclei can be easily distinguished as well as cell boundaries. After AuNP treatment and washing with fresh medium, free NP or NP aggregates can still be clearly seen in the cell surroundings (black dots). An unambiguous punctuated pattern inside the cell cytoplasm can also reproducibly be shown, especially in perinuclear areas. This strongly suggests an internalization process.
Whether this process is active (endocytosis) or passive (permeation) could not be addressed by this microscopy experiment. However, it has been shown elsewhere and on different cell types that the majority of $1.9 \mathrm{~nm}$ particles are endocytosed. ${ }^{25}$ While on F98 cells, the size of the dots was quite the same inside and outside of the cells, on U87-MG cells, the size of the black dots seems to indicate that the AuNP are aggregated. This might occur due to the intrinsic differences between the endocytosis processes in both cell lines.

\subsection{Biochemical effects induced by the AuNP without irradiation (0 Gy)}

Fig. 3 and 4 show the PCA scores and the corresponding loading plots on second derivative spectra for both F98 and U87-MG cell lines, respectively. PCA allows the reduction of the dimensionality of features in order to assess the similarities and differences between spectra. In the PCA score plot, each single point represents a cell spectrum. Loading plots express the influence of the variables that are responsible for each principal component as a function of the wavenumber. PCA analysis was performed separately in the fingerprint (1800-1000 $\left.\mathrm{cm}^{-1}\right)$ and lipid $\left(3100-2800 \mathrm{~cm}^{-1}\right)$ regions.

For the F98 glioma cell line, and prior to the radiotherapy irradiation (0 Gy), the PC1-PC2 plot in the fingerprint region shows a clear separation between NP-treated groups and the control group (-NP), mostly along PC-1, which explains $73 \%$ of the variance. PC- 1 shows more variance for the NP-treated groups. Fingerprint modifications are already observed at $T_{0 \mathrm{~h}}$, which gives us a first indication of the AuNP action. For the U87-MG cell line, there is also some separation along PC-1 in
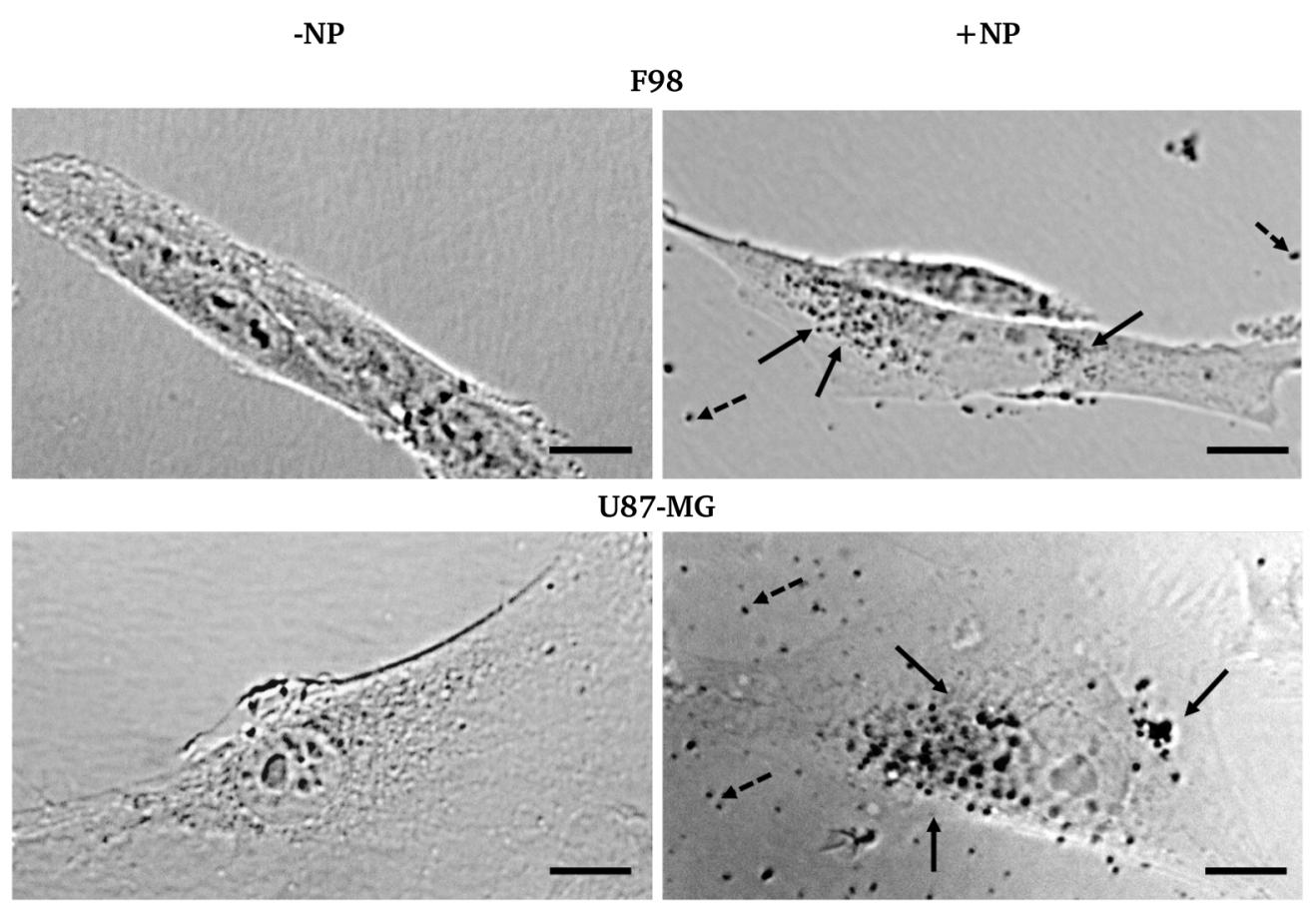

Fig. 2 Micrographs of two F98 cells (top) and U87-MG cells (bottom), without ('-NP', left) and with ('+NP', right) 24 hour incubation of $500 \mu \mathrm{g}$ $\mathrm{mL}^{-1}$ AuNP. Bar $=10 \mu \mathrm{m}$. Arrows $=$ AuNP (plain: inside cell; dotted: free AuNP). 
Fingerprint

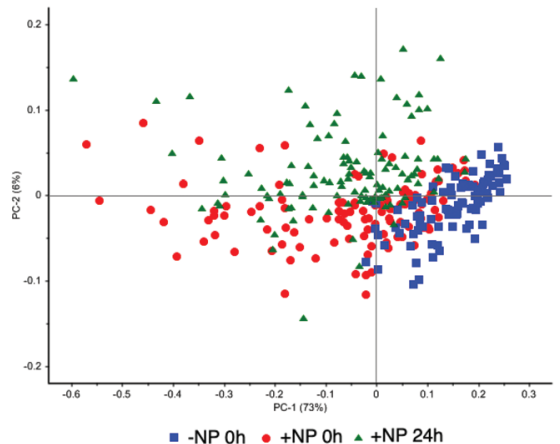

Lipids

PCA

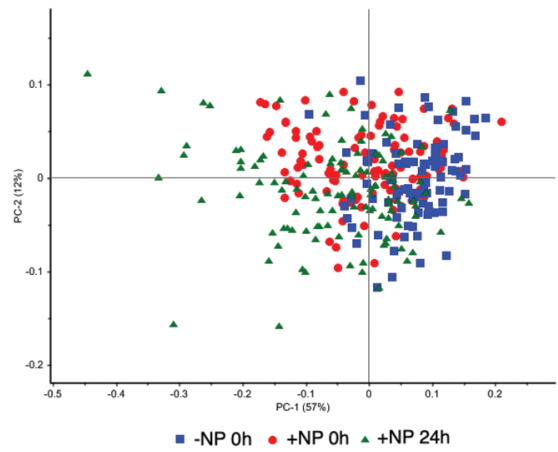

Loadings
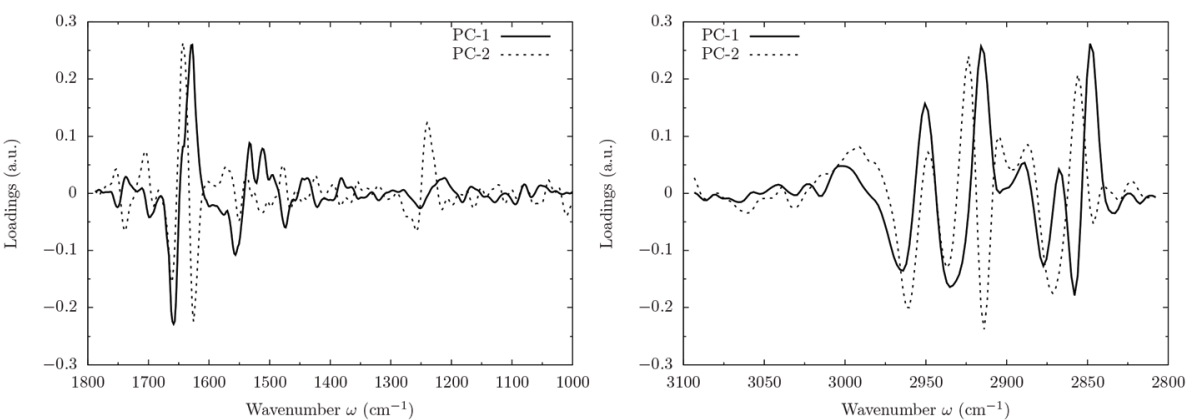

Fig. 3 F98 glioma cells: biochemical effects induced by the AuNP prior to irradiation (0 Gy). The PCA scores (top) and the corresponding loading plots (bottom) are presented in the fingerprint $\left(1800-1000 \mathrm{~cm}^{-1}\right.$; left) and lipid $\left(3100-2800 \mathrm{~cm}^{-1}\right.$; right) spectral regions in the presence ('+NP') and absence ('-NP') of nanoparticles at two post-irradiation fixation times ( $0 \mathrm{~h}$ and $24 \mathrm{~h})$.

the score plot between the control and NP-treated cells in the fingerprint region mainly at $T_{\mathrm{oh}}$.

The loading plots in the fingerprint region indicate that the largest biochemical changes induced by the NP are associated with protein modifications in the region of $1700-1500 \mathrm{~cm}^{-1}$ for both F98 and U87-MG cell lines. The vector normalized Savitzky-Golay second derivative calculated in the averaged absorbance spectra (Fig. 5) shows NP-induced changes in the protein conformational structures in the amide I and amide II bands, especially in the F98 glioma cell line. These bands are characteristic of peptide bonds of cell peptides and proteins. More precisely, there is a more explicit $\beta$-type secondary structure inside the NP-treated cells, ${ }^{34-36}$ which could be related to an initial apoptotic response of the cells, since previous studies have reported changes in the expression of pre-apoptotic proteins using the same type of NP. ${ }^{25}$

The separation of the NP-treated group at $T_{24 \mathrm{~h}}$ along PC-2 also has some contribution of the asymmetric phosphodiester band of the DNA $\left(1238 \mathrm{~cm}^{-1}\right)$, particularly in the case of the F98 cell line. We observe a shift towards the low frequency region for NP-treated cells (see Fig. 5). This shift has been observed in our previous work using gadolinium NP. ${ }^{21,27} \mathrm{We}$ also observe changes in the distribution of the relative intensities of several DNA spectral bands (PhI/AII, PhII/AII), as shown in Fig. 6 (top). At $T_{24 \mathrm{~h}}$, there is a slight decrease in the PhII/AII ratio in the case of U87-MG cells, which might be correlated to cell cycle changes and, particularly, to an increase in the sub $\mathrm{G}_{1}$ cell population induced by these AuNP. ${ }^{25}$ Previous studies have reported similar changes in the DNA region of the infrared spectra due to cell cycle modifications. ${ }^{36,37}$ Finally, it is important to note that we clearly observe an increase in the variance of the DNA biochemical content in NP-treated cells with respect to controls (-NP) both at $T_{0 \mathrm{~h}}$ and $T_{24 \mathrm{~h}}$ and for both cell lines, as a result of different NP-cell interaction mechanisms.

In the region of $3000-2800 \mathrm{~cm}^{-1}$, mostly representative of fatty acids encountered in the membranes, there is a separation between the scores of control cells and NP-treated cells in F98 glioma line (Fig. 3). NP-treated cells are correlated with peaks at $2848 \mathrm{~cm}^{-1}$ and $2915 \mathrm{~cm}^{-1}$, while control cells are correlated with peaks at $2935 \mathrm{~cm}^{-1}$ and $2858 \mathrm{~cm}^{-1}$. This corresponds to changes in the asymmetric and symmetric vibrations of $\mathrm{CH}_{2}$ stretching groups. ${ }^{38}$ Changes in these peaks were previously related to the changes in the lipid structure and chain length due to oxidative stress and membrane peroxidation. ${ }^{38-41}$ The separation in the PCA scores between -NP and +NP groups is less clear in the case of U87MG cells (Fig. 4). 
U87-MG

Fingerprint

Lipids

PCA
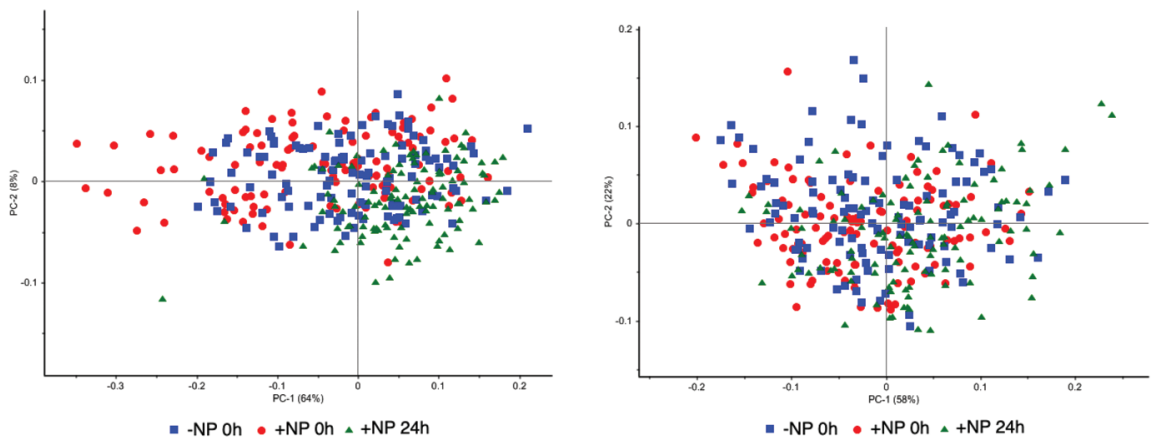

Loadings
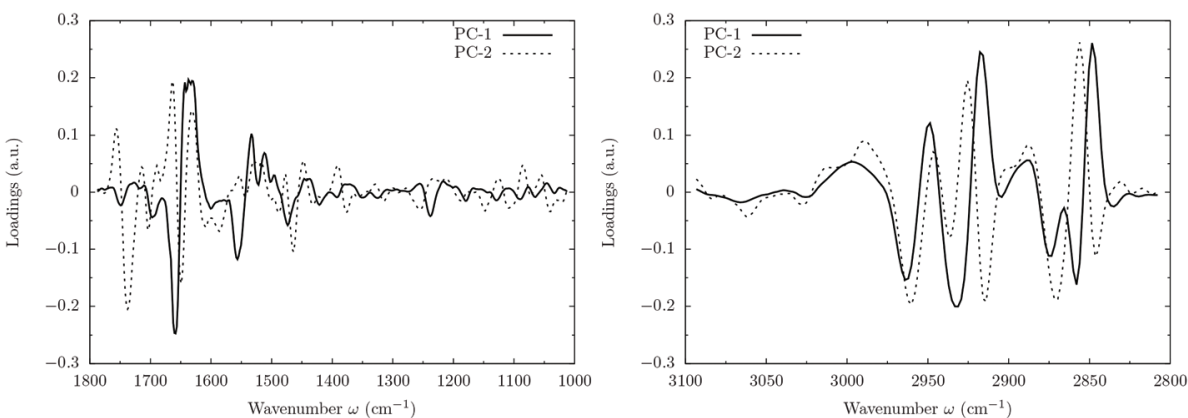

Fig. 4 U87-MG glioma cells: biochemical effects induced by the AuNP prior to irradiation (0 Gy). The PCA scores (top) and the corresponding loading plots (bottom) are presented in the fingerprint $\left(1800-1000 \mathrm{~cm}^{-1}\right.$; left) and lipid $\left(3100-2800 \mathrm{~cm}^{-1}\right.$; right) spectral regions in the presence $\left('+N P^{\prime}\right)$ and absence ('-NP') of nanoparticles at two post-irradiation fixation times ( $0 \mathrm{~h}$ and $24 \mathrm{~h}$ ).

F98

U87-MG

Fingerprint
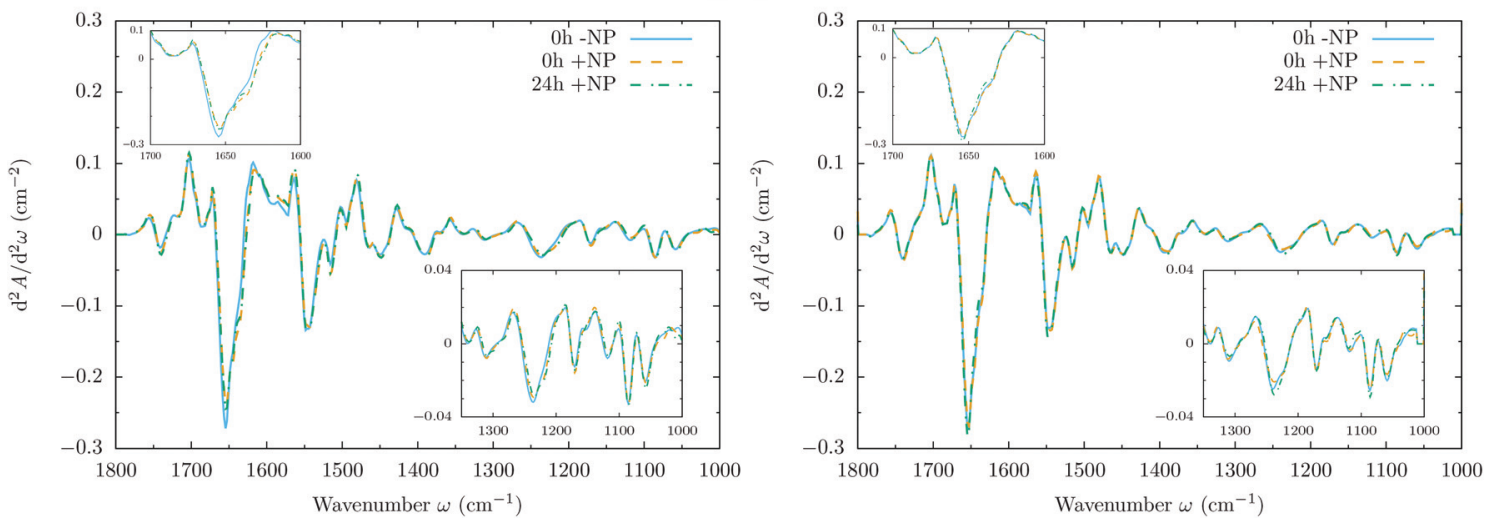

Fig. 5 F98 (left) and U87-MG (right) glioma cells: biochemical effects induced by the AuNP prior to irradiation (0 Gy). The vector normalized Savitzky-Golay second derivative calculated in the averaged absorbance spectra is shown for the -NP and +NP controls at two post-irradiation fixation times $(0 \mathrm{~h}$ and $24 \mathrm{~h})$ in the fingerprint $\left(1800-1000 \mathrm{~cm}^{-1}\right)$ spectral region. The insets show a zoom of the $1700-1600 \mathrm{~cm}^{-1}$ and $1350-1000 \mathrm{~cm}^{-1}$ regions.

The violin plots in Fig. 6 (bottom) show a clear increase in the $\mathrm{CH}_{2} / \mathrm{CH}_{3}$ ratio distribution for F98 cells (both at $T_{0 \mathrm{~h}}$ and $T_{24 \mathrm{~h}}$ ), which might indicate evidences of oxidative stress. ${ }^{39,40}$ There are also indications of oxidative stress in the U87-MG cells after NP- treatment $\left(T_{0 \mathrm{~h}}\right)$, which seems to be reduced at $T_{24 \mathrm{~h}}$. The induction of AuNP-related oxidative stress has been previously reported using the same type of NP via increased production of endogenous reactive oxygen species and depletion of intracellular antioxidants. ${ }^{25,42}$ 


\section{PhI/AII \& PhII/AII}
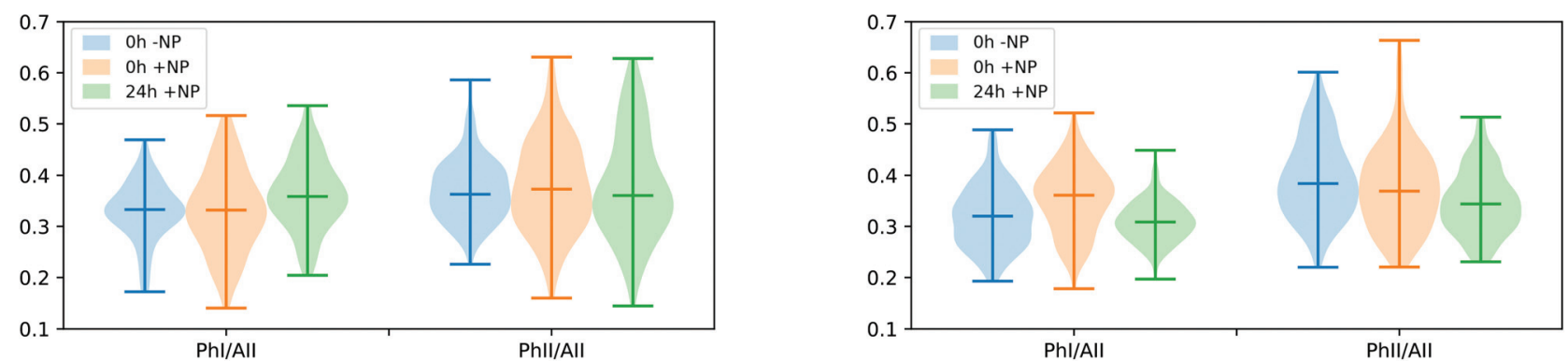

$\mathrm{CH}_{2} / \mathrm{CH}_{3}$
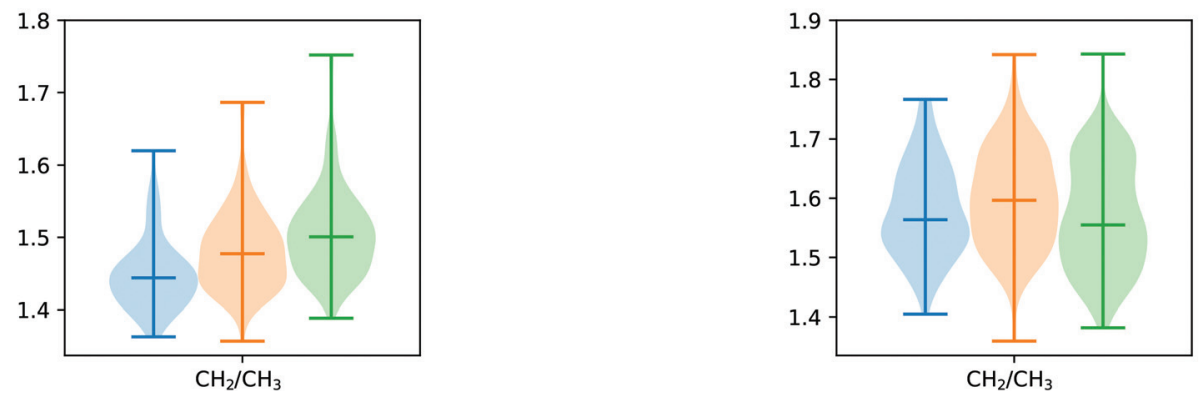

Fig. 6 F98 (left) and U87-MG (right) glioma cells: biochemical effects induced by the AuNP prior to irradiation (0 Gy). The violin plots are showing the distribution of the relative intensities of several spectral band ratios (Phl/All, PII/All and $\mathrm{CH}_{2} / \mathrm{CH}_{3}$; see section 2.6 for more information) for the $-\mathrm{NP}$ (blue) and +NP controls at two fixation times ( $0 \mathrm{~h}$, in orange; $24 \mathrm{~h}$ in green).

Our findings evidence a different biochemical response depending on the tumor cell model, which could be related to a different radiosensitization capability according to NP localization, NP-cell interaction processes or degree of sensitivity to oxidative damage or others. ${ }^{5,25,26}$ This could explain the differences in NP internalization relative to the cell type shown in the microscopy pictures (see Fig. 2) and might be related to the subsequent variations in the biochemical effects observed by SR-FTIRM.

\subsection{SR-FTIRM study on the radiosensitization effects at several radiation doses}

Fig. 7 and 8 show the PCA scores and the corresponding loading plots on second derivative spectra for both F98 and U87-MG cell lines, respectively, and several configurations: doses (from 5 to $20 \mathrm{~Gy}$ ), with/without NP (-NP/+NP) and postirradiation times $\left(T_{0 \mathrm{~h}} / T_{24 \mathrm{~h}}\right)$. PCA scores were separated as a function of the dose to assess the effect of AuNP for the same irradiation conditions. The two fixation times are compared in the same PCA scores to assess cell response to the treatments as a function of time.

In F98 glioma cells, the protein region of the fingerprint spectral range $\left(1700-1500 \mathrm{~cm}^{-1}\right)$ is the main factor responsible for PCA score separation. PC1-PC2 score plots display clearly separated clusters (-NP/NP and $T_{0 \mathrm{~h}} / T_{24 \mathrm{~h}}$ ), particularly for $10 \mathrm{~Gy}$ and $20 \mathrm{~Gy}$ and in the case of $T_{24 \mathrm{~h}}$. PC-1 and PC-2 take into account around $70 \%$ and $10 \%$ of the variance, respectively, for all doses. The loading plots show that wavenumbers around $1628 \mathrm{~cm}^{-1}$ are highly correlated to NPtreated groups, while wavenumbers around $1660^{-1}$ are correlated to irradiated groups without AuNP. This correlation is better manifested at $T_{24 \mathrm{~h}}$. While the first is attributed to the $\beta$-sheet conformation of the amide I band, the second one is assigned to the $\alpha$-helix form. ${ }^{34}$ This indicates a shift towards lower wavenumbers in the amide for irradiated cells in the presence of AuNP, as can be seen in Fig. 9 (left). Previous studies correlated this shift to an increase in disordered structures due to protein denaturation..$^{43}$ In our case, the secondary protein structure changes inside the cells correlated with protein unfolding and/or denaturation might be related to cell death under treatment-induced stress. ${ }^{36,44}$ This stress could be enhanced by the increased generation of ROS due to the presence of AuNP, which has been associated with changes in the amide I and II bands. ${ }^{44-46}$ An amplification in the apoptotic response of irradiated cells in the presence of AuNP is in accordance with our previous FTIRM study using gadolinium NP. ${ }^{21,27}$ The protein modifications as a function of the treatment are clearly shown on the vector normalized Savitzky-Golay second derivative plot (Fig. 9, left). 
Fingerprint - F98

5 Gy
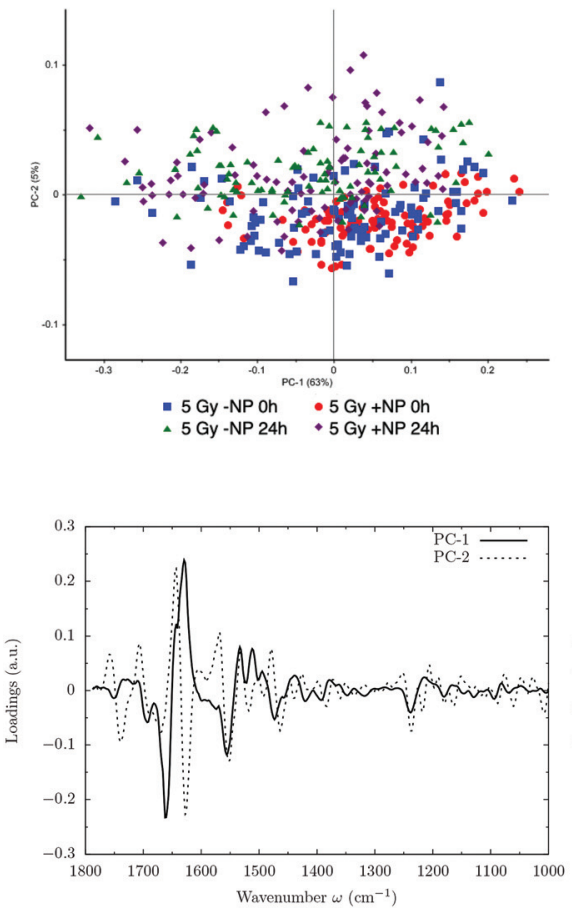

5 Gy

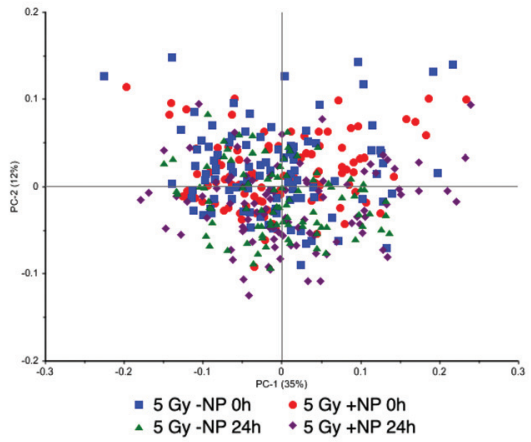

5 Gy -NP Oh $\bullet 5$ Gy +NP Oh
5 Gy -NP 24h $\quad 5$ Gy +NP 24h

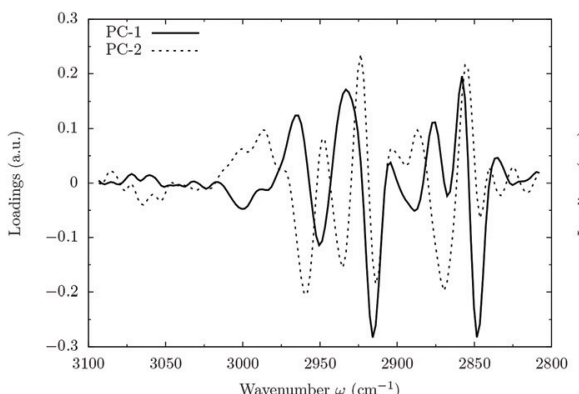

$10 \mathrm{~Gy}$

PCA

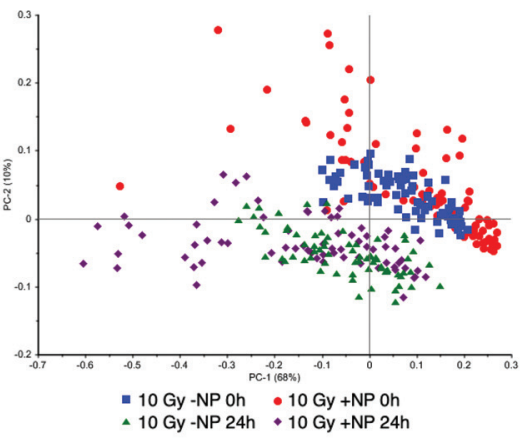

Loadings

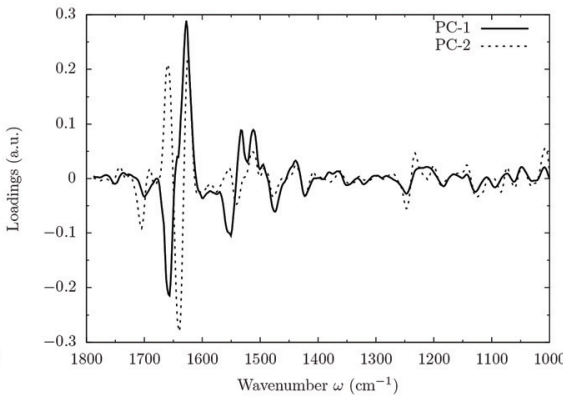

Lipids - F98

$10 \mathrm{~Gy}$

PCA

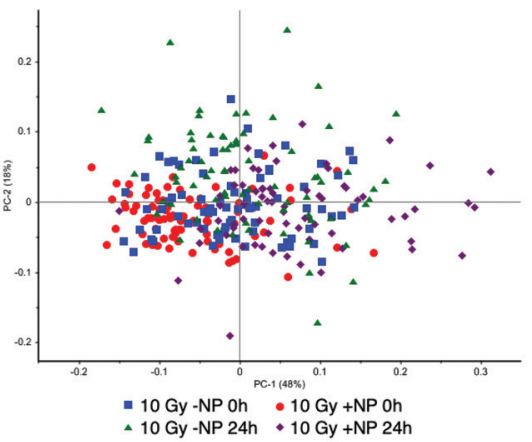

Loadings

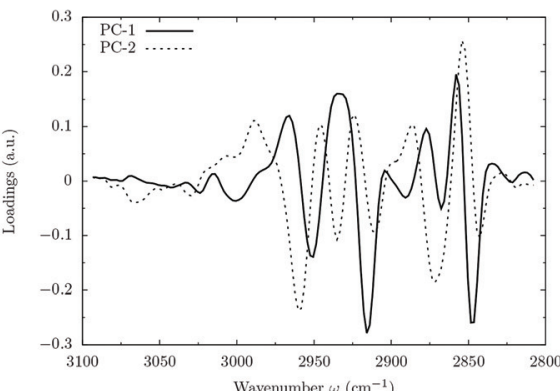

$20 \mathrm{~Gy}$
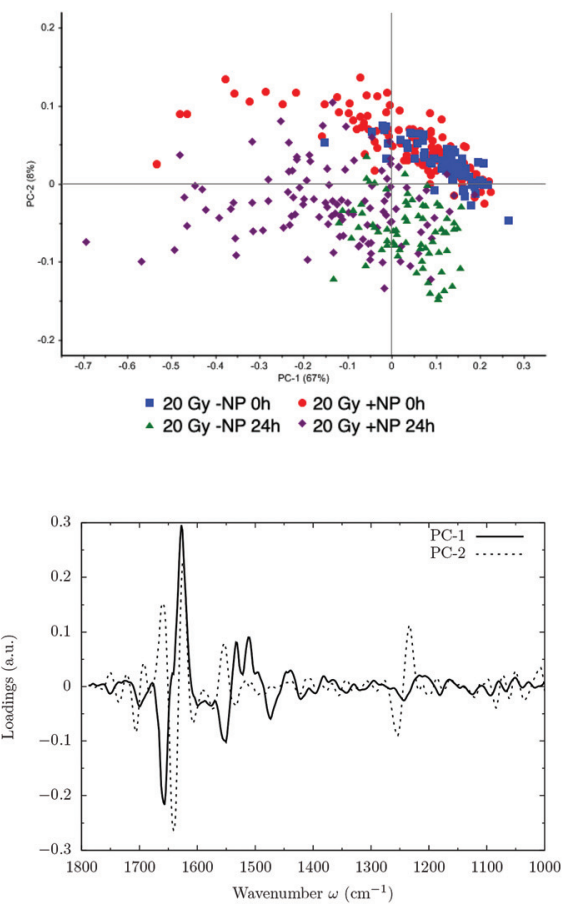

$20 \mathrm{~Gy}$
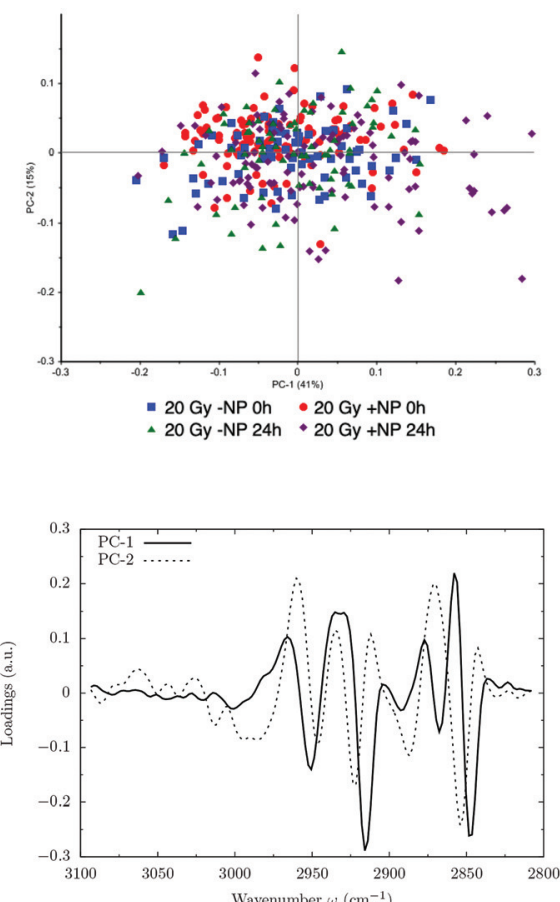

Fig. 7 F98 glioma cells: radiosensitization effects of AuNP for several doses: 5 Gy (left), 10 Gy (center) and 20 Gy (right). The PCA scores and the corresponding loading plots are presented in the fingerprint $\left(1800-1000 \mathrm{~cm}^{-1}\right.$; top) and lipid $\left(3100-2800 \mathrm{~cm}^{-1}\right.$; bottom) spectral regions. 
Fingerprint - U87-MG

5 Gy

$10 \mathrm{~Gy}$

PCA
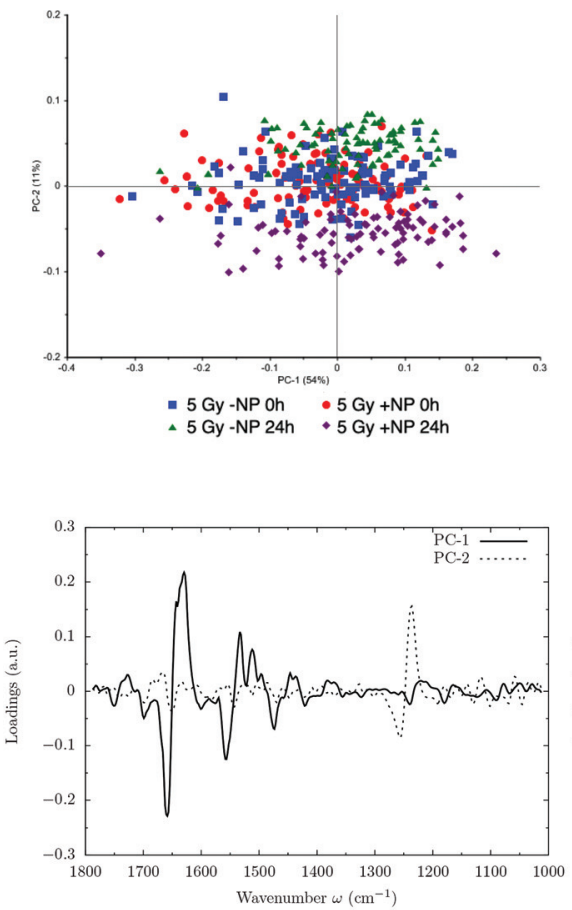

5 Gy
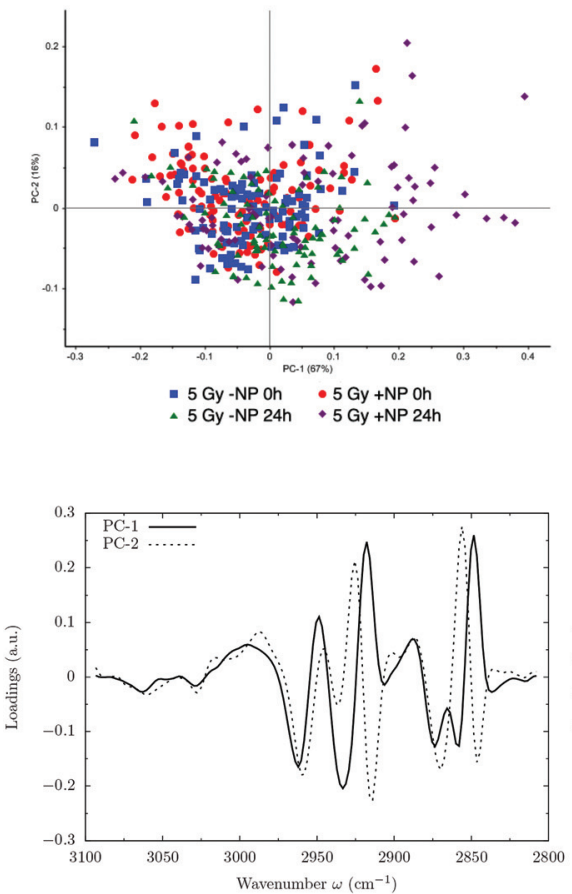

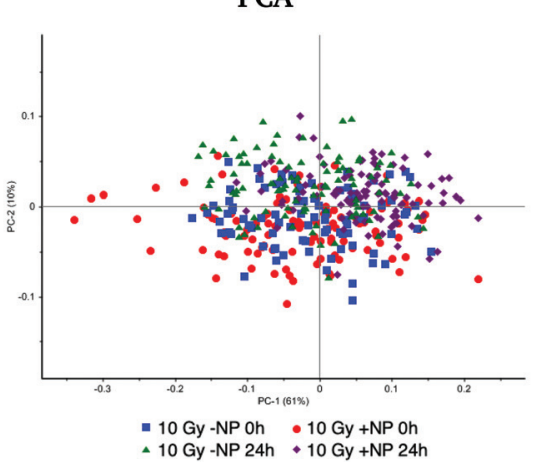

Loadings

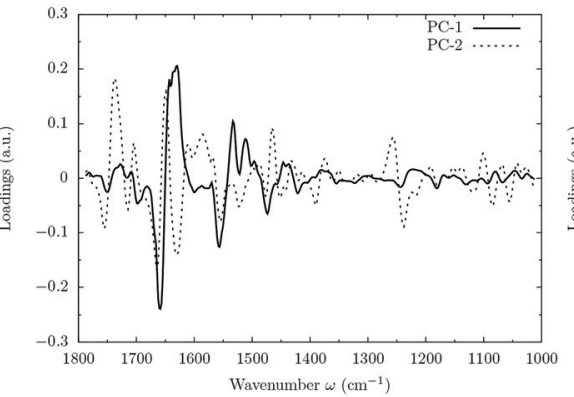

Lipids - U87-MG

$10 \mathrm{~Gy}$

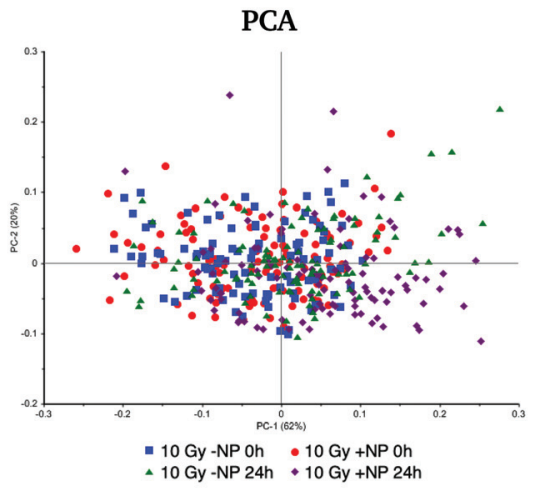

Loadings

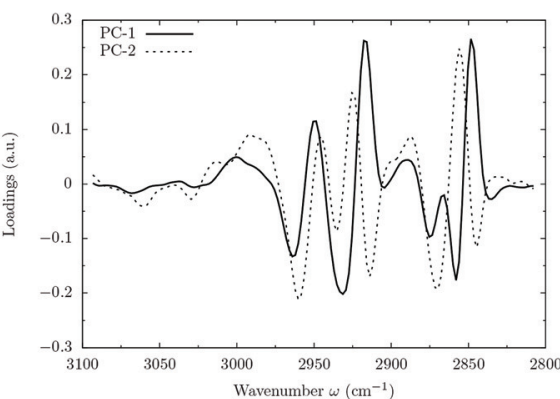

$20 \mathrm{~Gy}$
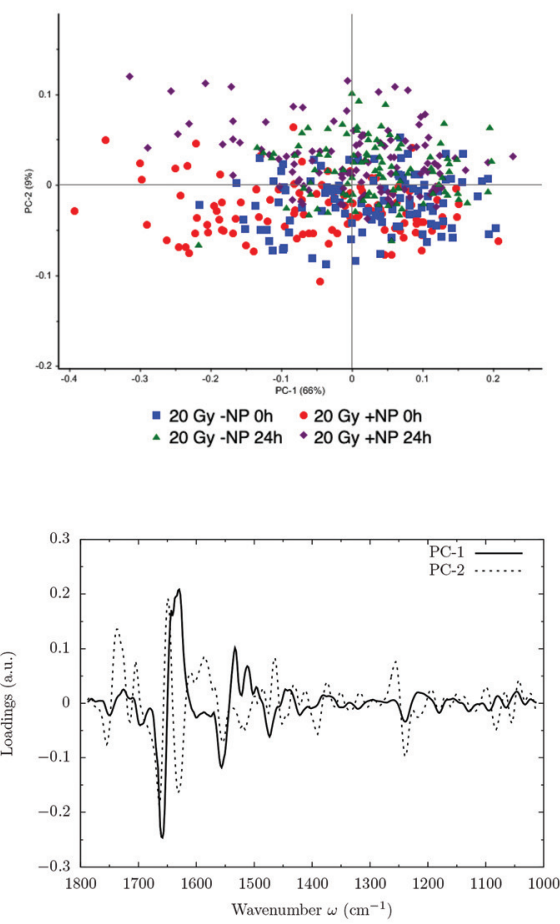

20 Gy
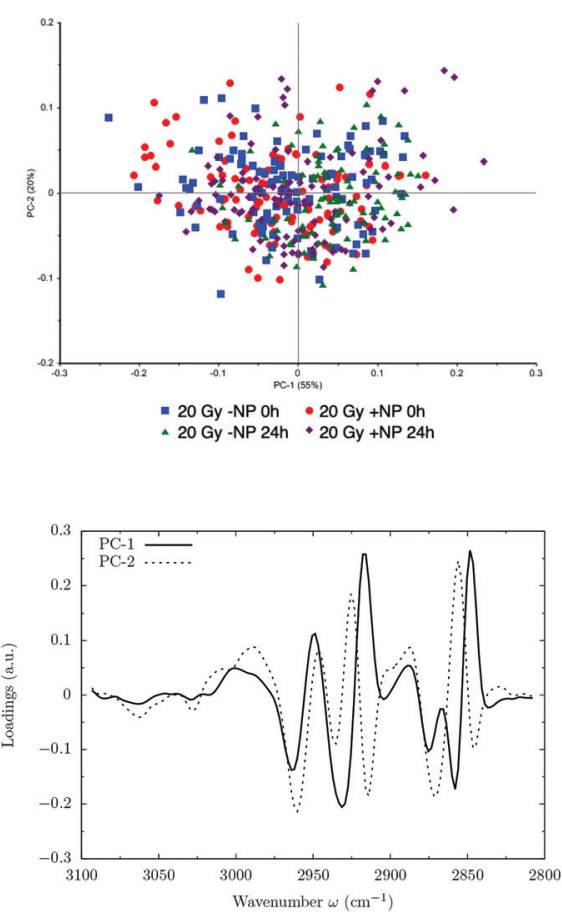

Fig. 8 U87-MG glioma cells: radiosensitization effects of AuNP for several doses 5 Gy (left), 10 Gy (center) and 20 Gy (right). The PCA scores and the corresponding loading plots are presented in the fingerprint $\left(1800-1000 \mathrm{~cm}^{-1}\right.$; top) and lipid $\left(3100-2800 \mathrm{~cm}^{-1}\right.$; bottom) spectral regions. 


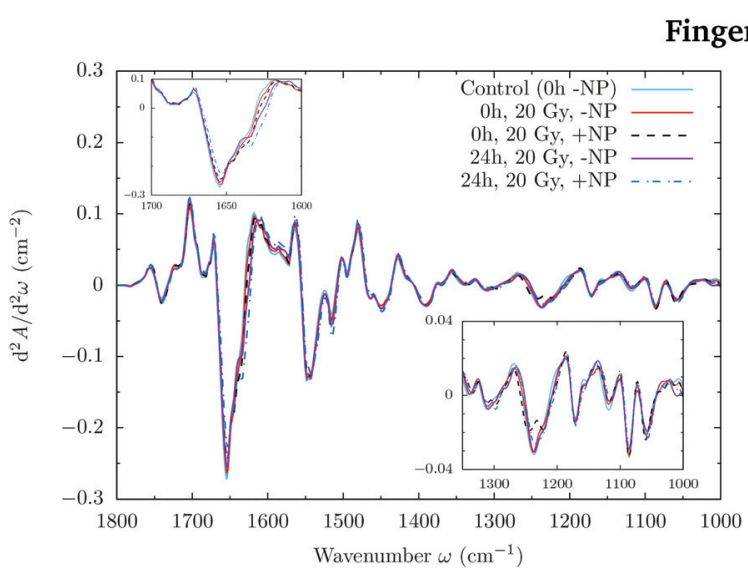

Fingerprint

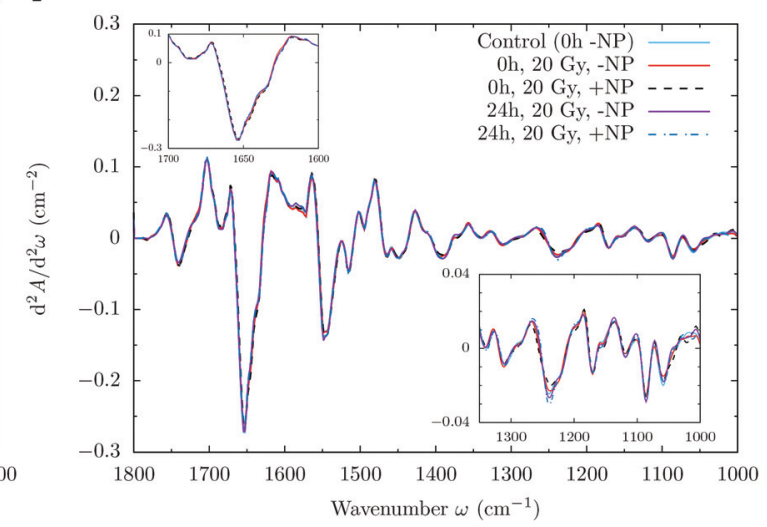

Fig. 9 F98 (left) and U87-MG (right) glioma cells: radiosensitization effects of AuNP (20 Gy). The vector normalized Savitzky-Golay second derivative calculated in the averaged absorbance spectra is shown for the -NP and +NP controls at two post-irradiation fixation times $(0 \mathrm{~h}$ and $24 \mathrm{~h})$ in the fingerprint $\left(1800-1000 \mathrm{~cm}^{-1}\right)$ spectral region. The insets show a zoom of the $1700-1600 \mathrm{~cm}^{-1}$ and $1350-1000 \mathrm{~cm}^{-1}$ regions.

In the case of U87-MG cells, the effect is less clear since the PC1-PC2 scores in the fingerprint region show more overlapping between '-NP' and '+NP' groups. For 20 Gy, we observe a slight separation of the NP-treated group for both fixation times. Loading plots mainly correlate this separation with secondary protein structure changes and modifications in the asymmetric phosphodiester bands. These changes, amplified in the presence of NP, are probably related to an enhanced cell death response due to the combination of radiation damage and AuNP-induced biochemical modifications. However, we observed a reduced biochemical response to AuNP with respect to F98 cells in the presence of radiation, since secondary structure protein changes are less clear in the SavitzkyGolay second derivative plot (Fig. 9, right).

Fig. 10 shows the distribution of the relative intensities of several spectral band ratios (PhI/AII, PhII/AII, AI/AII and $\mathrm{CH}_{2} /$ $\mathrm{CH}_{3}$ ) defined in section 2.6. For the F98 cell line, we observe a decrease in the absorbance of the AI/AII ratio in NP-treated cells. Changes in the amide I and amide II absorbance were previously related to DNA repair processes, which involves many enzymes to repair the damage produced by the ionizing radiation. ${ }^{47,48}$ The changes in relative intensity between the areas in amide I and amide II bands have also been correlated with the biochemical changes of cellular proteins following apoptosis, which affects the overall protein folding and localization and thus, the infrared absorption of peptide bonds..$^{30,31}$

By looking into the DNA region $\left(1350-1000 \mathrm{~cm}^{-1}\right)$ in the vector normalized Savitzky-Golay second derivative plot (Fig. 9), which is assigned to phosphodiester groups mostly found in nucleic acids, we observe several changes in the intensity and position (shifts) of several peaks. This probably implies a number of different variations in DNA organization or local conformation as a result of radiation damage, which is amplified in the presence of AuNP. The investigation of the loadings shows a slight variance emerging from the asymmetric phosphodiester band of the DNA at $1238 \mathrm{~cm}^{-1}$ for NP- treated groups at $T_{24 \mathrm{~h}}$. The differential biochemical response to AuNP in the DNA region is more visible in the case of F98 than in the case of U87-MG cells.

For F98 glioma cells, the violin plots of Fig. 10 show a slight reduction in the PhII/AII ratio for NP-treated cells at $T_{24 \mathrm{~h}}$, which has been previously correlated with chromatin fragmentation and apoptotic DNA condensation in previous studies. $^{28,30,49}$ Previous studies have reported similar variations as a result of radiation damage. ${ }^{31,44,47,49}$ Instead, U87MG cells exhibit a clear increase in the PhI/AII and PhII/AII ratios at $T_{24 \mathrm{~h}}$ in NP-treated cells. An increase in the phosphodiester bands was already observed in the work of Lipiec and collaborators for PC-3 (human prostate adenocarcinoma) cells following proton irradiation. ${ }^{47}$ The increase in the intensity of the DNA backbone was correlated with multiple DNA breakages. ${ }^{47,50}$

When comparing NP-treated cells in the lipid region (3100-2800 $\mathrm{cm}^{-1}$ ), the score plots do not display clear separated clusters, despite the fact that the NP-treated groups at $T_{24 \mathrm{~h}}$ seem to be slightly separated towards positive PC- 1 in both cell lines from the other groups $\left(T_{0 \mathrm{~h}}\right.$ and $T_{24 \mathrm{~h}}$ without AuNP). Fig. 10 shows some increase in $\mathrm{CH}_{2} / \mathrm{CH}_{3}$ ratio distribution (defined in section 2.6) at $T_{24 \mathrm{~h}}$, which is more marked for U87-MG cells. The higher absorbance in the $\mathrm{CH}_{2}$ asymmetric stretching mode with respect to the $\mathrm{CH}_{3}$ asymmetric stretching has been reported with cell death processes in previous studies. ${ }^{28}$ Indeed, a higher $\mathrm{CH}_{2} / \mathrm{CH}_{3}$ ratio has been determined for apoptotic cells by proton nuclear magnetic resonance spectroscopy in previous studies..$^{51-53}$

Finally, it is important to remark that we observe a higher intra-cellular variation in treated cells, demonstrating the heterogeneity in the biochemical cell response among the same cell population and also among cell lines. This is probably due to different NP-cell interaction processes, and degree of sensitivity to oxidative/radiation damage or others. The radiosensitization potential dependence as a function of the cell type has 
PhI/AII \& PhII/AII
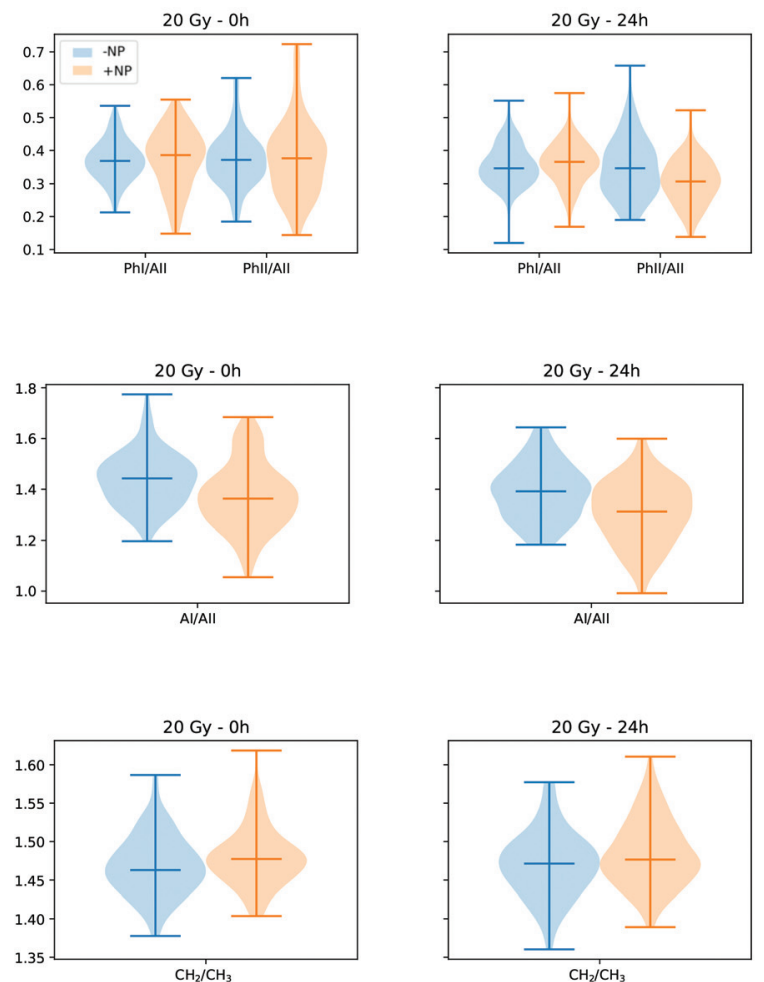
'+NP' (orange) controls at two post-irradiation fixation times ( $0 \mathrm{~h}$ and $24 \mathrm{~h})$.
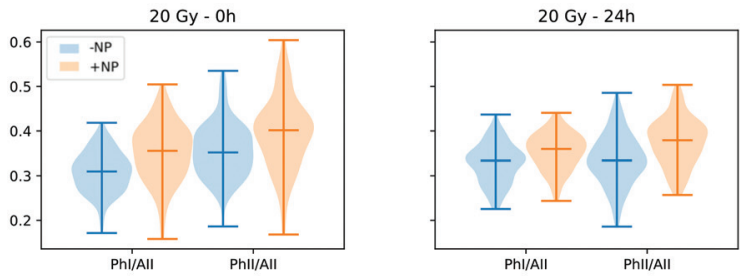

$\mathrm{AI} / \mathrm{AII}$
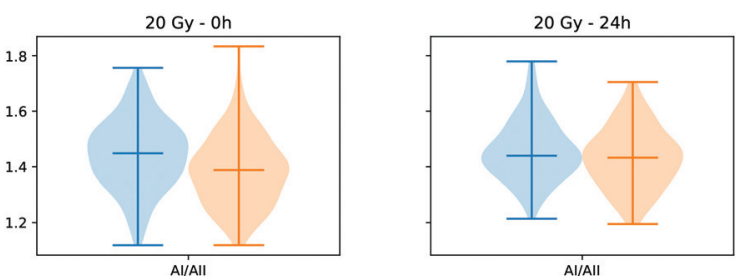

$\mathrm{CH}_{2} / \mathrm{CH}_{3}$
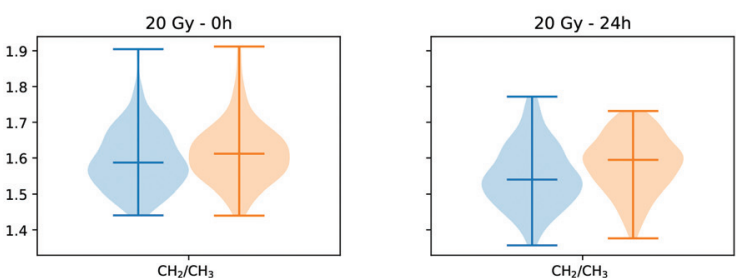

Fig. 10 F98 (left) and U87-MG (right) glioma cells: radiosensitization effects of AuNP (20 Gy). The violin plots are showing the distribution of the relative intensities of several spectral band ratios (Phl/All, Phll/All, Al/All and $\mathrm{CH}_{2} / \mathrm{CH}_{3}$; see section 2.6 for more information) for the '-NP' (blue) and
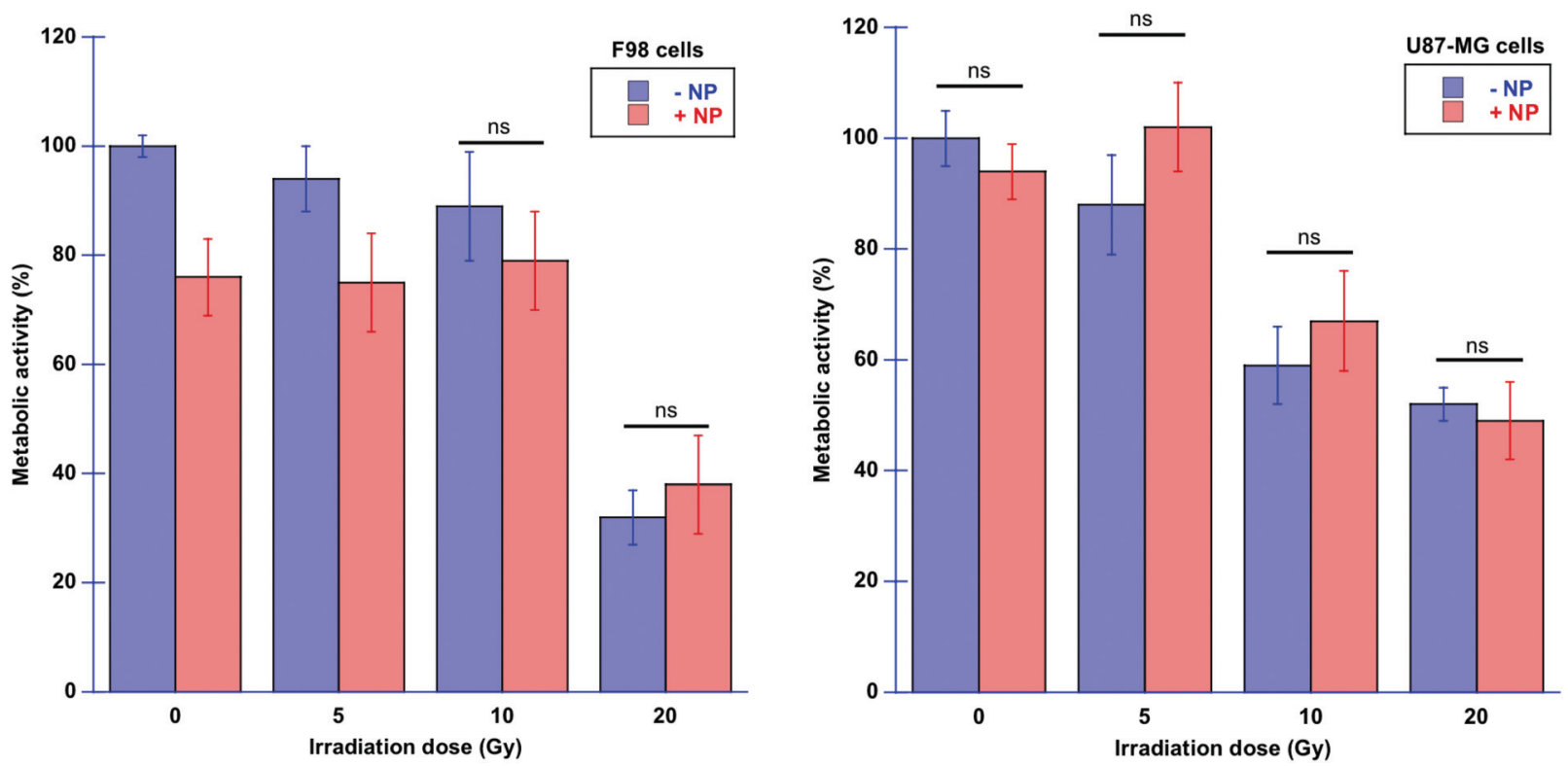

Fig. 11 Metabolic activity of F98 cells (left) and U87-MG cells (right) with and without NP for several doses of radiation. The control cell group was considered to have $100 \%$ of living cells. The values obtained with the different cell treatments were normalized using the values of the control cell group. Data are presented as the mean and standard error of the mean (SEM). Statistical significance in the analysis of the effect of the radiation dose, with or without NP, was determined using a standard two-tailed unpaired $t$-test. If any, non-significant differences (ns) with $p \geq 0.05$ are indicated on the graphs. 
also been reported in previous studies using the same type of NP. 5,25,26,54 The distinct cellular responses of different cell lines are a key point for the study of radiosensitization effects of NP. Within this context, SR-FTIRM can provide new insights into the molecular and cellular levels for understanding the complex radiosensitization processes involving nanoparticles and radiotherapy, as shown in this work.

\subsection{Cell viability assay}

Fig. 11 shows the results of the resazurin-resorufin proliferation assay performed on treated cells, with or without AuNP, and with or without X-ray irradiations at 24 hours postirradiation time, to correlate with respect to the infrared data at $T_{24 \mathrm{~h}}$.

F98 glioma cells seem to be more sensitive to AuNP, already in the absence of radiation. Also, in the presence of radiation, U87-MG cells seem to be less sensitive to AuNP compared to F98 cells since the metabolic activity is not significantly different in the presence of AuNP. In F98 glioma cells, we can observe significant changes for the lowest dose (5 Gy), since the F98 metabolic activity is decreased in the presence of AuNP. It is interesting to note that the macroscopical measurement of the metabolic activity through the proliferation assay does not allow the differentiation of the effect of AuNP on both cell lines in all configurations, whereas SR-FTIRM shows more detailed events occurring at the molecular level. In this study, the choice of performing the proliferation test at 24 hours post-irradiation was to be able to correlate with the SR-FTIRM data and early biological events. Larger effects might be expected at larger post-irradiation times, as reported in previous studies using the same type of NP. ${ }^{25}$

\section{Conclusions}

Despite significant evidence on the radiosensitization effects of AuNP, the exact mechanisms of radiosensitization are not clear. This work constitutes the first study of the radiosensitization effects of $1.9 \mathrm{~nm}$ AuNP in the F98 and U87-MG glioma cell lines by synchrotron-based infrared microspectroscopy at the single-cell scale. SR-FTIRM is a powerful tool for monitoring biochemical changes induced by AuNP combined with radiotherapy for assessing different cell responses to the treatments.

Cell-NP interactions differ in both cell lines. Prior to irradiation, AuNP induced spectral variations were observed both in the fingerprint and in the lipid regions. In particular, initial conformational changes in the protein secondary structures (F98, U87-MG), an increase in the $\mathrm{CH}_{2} / \mathrm{CH}_{3}$ ratio (F98 cells), and absorbance intensity variations in the phosphodiester vibrations of the DNA (U87-MG) are detected. The biochemical alterations induced by the AuNP on both cell lines give us a first indication on the AuNP action.

PCA analysis reveals clear NP-induced changes when AuNP are combined with radiotherapy. The main spectral variations include a shift toward the low wavenumber in the protein bands (F98), changes in amide I/II relative intensity (F98), and relative amplitude changes in the $\mathrm{CH}_{2}$ and $\mathrm{CH}_{3}$ stretching modes (U87-MG), along with several DNA organization or local conformation modifications (F98, U87-MG) due to the presence of AuNP. These changes are better manifested at $T_{24 \mathrm{~h}}$ and they are probably related to an initial cell death response of the cells, which is amplified in the presence of AuNP. SR-FTIRM results showed the heterogeneity in the biochemical cell response among different cell lines (and among the same cell population), probably due to the different NP-cell interaction processes, degree of sensitivity to oxidative/radiation damage, etc., which implies different radiosensitization capabilities as a function of the cell line.

Despite the fact that SR-FTIRM provides a deeper understanding of the NP-induced molecular and cellular response at a biochemical level, further biological studies are required to assess the role of different (physical and biochemical) radiosensitization mechanisms as a function of NP and cell type. Comprehensive characterization studies of cellular responses to AuNP are required for the further development of this promising technique towards potential clinical translation.

\section{Conflicts of interest}

There are no conflicts to declare.

\section{Acknowledgements}

The authors acknowledge the granted beamtime at ALBA-CELLS Synchrotron. We also thank Dr S. Heinrich, Dr F. Pouzoulet (Institut Curie, France) and Dr F. Gaudin (Institut Paris-Sud d'Innovation Thérapeutique, France) for their technical support.

This project has received funding from the European Union Horizon 2020 Framework Programme under the Marie Sklodowska-Curie grant agreement number 748889 .

\section{References}

1 J. F. Hainfeld, D. N. Slatkin and H. M. Smilowitz, Phys. Med. Biol., 2004, 49, 309-315.

2 D. Kwatra, A. Venugopal and S. Anant, Transl. Cancer Res., 2013, 2, 330-342.

3 M. Babaei and M. Ganjalikhani, BioImpacts, 2014, 4, 15-20.

4 K. Haume, S. Rosa, S. Grellet, M. A. Smialek, K. T. Butterworth, A. V. Solovyov, K. M. Prise, J. Golding and N. J. Mason, Cancer Nanotechnol., 2016, 7, 1-20.

5 S. Her, D. A. Jaffray and C. Allen, Adv. Drug Delivery Rev., 2017, 109, 84-101.

6 Y. Matsumura and H. Maeda, Cancer Res., 1986, 46, 6387-6392.

7 S. Akhter, M. Z. Ahmad, F. J. Ahmad, G. Storm and R. J. Kok, Expert Opin. Drug Delivery, 2012, 9, 1225-1243.

8 S. Jain, D. Hirst and J. O'Sullivan, Br. J. Radiol., 2009, 85, 101-113. 
9 W. Ngwa, R. Kumar, S. Sridhar, H. Korideck, P. Zygmanski, R. A. Cormack, R. Berbeco and G. M. Makrigiorgos, Nanomedicine, 2014, 9, 1063-1082.

10 I. Martínez-Rovira and Y. Prezado, Med. Phys., 2011, 38, 4430-4439.

11 Y. Pan, A. Leifert, D. Ruau, S. Neuss, J. Bornemann, G. Schmid, W. Brandau, U. Simon and W. Jahnen-Dechent, Small, 2009, 5, 2067-2076.

12 K. Butterworth, S. McMahon, F. Currel and K. Prise, Nanoscale, 2012, 4, 4830-4838.

13 S. Rosa, C. Connolly, G. Schettino, K. T. Butterworth and K. M. Prise, Cancer Nanotechnol., 2017, 8, 1-25.

14 D. Choudhury, P. Xavier, K. Chaudhari, R. John, A. Dasgupta, T. Pradeep and G. Chakrabarti, Nanoscale, 2013, 5, 4476-4489.

15 F. Taupin, M. Flaender, R. Delorme, T. Brochard, J.-F. Mayol, J. Arnaud, P. Perriat, L. Sancey, F. Lux, R. Barth, M. Carriere, J.-L. Ravanat and H. Elleaume, Phys. Med. Biol., 2015, 60, 4449-4464.

16 I. Martínez-Rovira and Y. Prezado, Med. Phys., 2015, 42, 6703. 17 M. J. Baker, J. Trevisan, P. Bassan, R. Bhargava, H. J. Butler, K. M. Dorling, P. R. Fielden, S. W. Fogarty, N. J. Fullwood, K. A. Heys, C. Hughes, P. Lasch, P. L. Martin-Hirsch, B. Obinaju, G. D. Sockalingum, J. Sulé-Suso, R. J. Strong, M. J. Walsh, B. R. Wood, P. Gardner and F. L. Martin, Nat. Protoc., 2014, 9, 1771-1791.

18 M. Diem, P. Griffiths and J. Chalmers, Vibrational spectroscopy for medical diagnosis, John Wiley \& Sons, New York, 2008.

19 I. Yousef, J. Breard, N. SidAhmed-Adrar, A. Maamer-Azzabi, C. Marchal, P. Dumas and F. Le Naour, Analyst, 2011, 136, 5162-5168.

20 L. Buriankova, Z. Nadova, D. Jancura, M. Refregiers, I. Yousef, J. Mikes and P. Miskovsky, Laser Phys. Lett., 2010, 7, 613.

21 I. Yousef, O. Seksek, Y. Prezado, J. Sulé-Suso and I. Martínez-Rovira, Analyst, 2016, 141, 2238-2249.

22 Nanoprobes, http://www.nanoprobes.com/.

23 R. Barth and B. Kaur, J. Neurooncol., 2009, 94, 299-312.

24 V. L. Jacobs, P. A. Valdes, W. F. Hickey and J. A. De Leo, ASN Neuro, 2015, 3, e00063.

25 J. A. Coulter, S. Jain, K. T. Butterworth, L. E. Taggart, G. R. Dickson, S. J. McMahon, W. B. Hyland, M. F. Muir, C. Trainor, A. R. Hounsell, J. M. O'Sullivan, G. Schettino, F. J. Currell, D. G. Hirst and K. M. Prise, Int. J. Nanomed., 2012, 7, 2673-2685.

26 K. T. Butterworth, J. A. Coulter, S. Jain, J. Forker, S. J. McMahon, G. Schettino, K. M. Prise, F. J. Currell and D. G. Hirst, Nanotechnology, 2010, 21, 2673-2685.

27 I. Martínez-Rovira, O. Seksek, J. Puxeu, J. Gómez, M. Kreuzer, T. Ducic, M. J. Ferreres, M. Artigues and I. Yousef, Analyst, 2019, 144, 5511-5520.

28 G. Birarda, D. E. Bedolla, E. Mitri, S. Pacor, G. Grenci and L. Vaccari, Analyst, 2014, 139, 3097.

29 A. Kretlow, Q. Wang, M. Beekes, D. Naumann and L. M. Miller, Biochim. Biophys. Acta, Mol. Basis Dis., 2008, 1782, 559-565.
30 F. Gasparri and M. Muzio, Biochem. J., 2003, 369, 239-248.

31 N. Gault and J. Lefaix, Radiat. Res., 2003, 160, 238-250.

32 Mammalian Cell Viability - Methods and Protocols, ed. M. J. Stoddart, Humana Press, 2011.

33 S. Anoopkumar-Dukie, J. B. Carey, T. Conere, E. O’Sullivan, F. N. van Pelt and A. Allshire, Br. J. Radiol., 2005, 78, 945947.

34 A. Barth, Biochim. Biophys. Acta, 2007, 1767, 1073-1101.

35 J. Sulé-Suso, D. Skingsleyc, G. Sockalingumd, A. Kohlere, G. Kegelaerd, M. Manfaitd and A. El Hajb, Vib. Spectrosc., 2005, 38, 179-184.

36 H. Holman, M. Martin, E. Blakely, K. Bjornstad and W. McKinney, Biopolymers, 2000, 57, 329-335.

37 D. E. Bedolla, S. Kenig, E. Mitri, P. Storici and L. Vaccari, Vib. Spectrosc., 2014, 75, 127-135.

38 C. Saulou, F. Jamme, L. Girbal, C. Maranges, I. Fourquaux, M. Cocaign-Bousquet, P. Dumas and M. Mercier-Bonin, Anal. Bioanal. Chem., 2013, 405, 2685-2697.

39 F. S. Ruggeri, C. Marcott, S. Dinarelli, G. Longo, M. Girasole, G. Dietler and T. P. J. Knowles, Int. J. Mol. Sci., 2018, 19, 2582.

40 A. Derenne, T. Claessens, C. Conus and E. Goormaghtigh, Infrared spectroscopy of membrane lipids, in Encyclopedia of Biophysics, ed. G. C. K. Roberts, Springer, Berlin/ Heidelberg, Germany, 2013.

41 C. Petibois and G. Deleris, Analyst, 2004, 129, 912-916.

42 Y. Pan, A. Leifert, D. Ruau, S. Neuss, J. Bornemann, G. Schmid, W. Brandau, U. Simon and W. Jahnen-Dechent, Small, 2009, 5, 2067-2076.

43 A. Bouhekka and T. Burgi, Appl. Surf. Sci., 2012, 261, 369374.

44 N. Gault, O. Rigaud, J. Poncy and J. Lefaix, Int. J. Radiat. Biol., 2005, 81, 767-779.

45 N. Gault, O. Rigaud, J. Poncy and J. Lefaix, Radiat. Res., 2007, 167, 551-562.

46 M. Sharma, J. C. Crosbie, L. Puskar and P. Rogers, Int. J. Radiat. Biol., 2013, 89, 79-87.

47 E. Lipiec, K. Bambery, P. Heraud, C. Hirschmugl, J. Lekki, W. Kwiatek, M. Tobin, C. Vogel, D. Whelan and B. Wood, J. Mol. Struct., 2014, 1073, 134-141.

48 A. Sancar and G. B. Sancar, Annu. Rev. Biochem., 1988, 57, 29-67.

49 A. Meade, C. Clarke, H. Byrne and F. Lyng, Radiat. Res., 2010, 173, 225-237.

50 K. Sailer, Int. J. Radiat. Biol., 1996, 69, 601-613.

51 G. Zhang, R. Zhu, Y. Xu, Y. Yan and Y. Dai, Acta Bot. Sin., 2004, 46, 711-718.

52 G. Blankenberg, P. Katsikis, R. Storrs, C. Beaulieu, D. Spielman, J. Chen, L. Naumovski and J. Tait, Blood, 1997, 89, 3778-3786.

53 N. M. S. Al-Saffar, J. C. Titley, D. Robertson, P. A. Clarke, L. E. Jackson, M. O. Leach and S. M. Ronen, Br. J. Cancer, 2002, 86, 963-970.

54 J. R. Nicol, E. Harrison, S. M. O’Neill, D. Dixon, H. O. McCarthy and J. A. Coulter, Nanomedicine, 2018, 14, 439-449. 